\title{
Jahrestagung 2011
}

Die 71. Jahrestagung der Vereinigung der Deutschen Staatsrechtslehrer e.V. fand vom 5. bis 8. Oktober 2011 an der Westfälischen Wilhelms-Universität Münster statt. An ihr nahmen etwa 460 Personen 380 Mitglieder sowie 80 Besucher (ausländische Gäste, Vertreter von juristischen Verlagen und Begleitpersonen) - teil. Es handelte sich nach der legendären Tagung von 1926 sowie der Tagung von 1962 - um das dritte Treffen der Vereinigung in Münster.

In der Mitgliederversammlung am 5. Oktober 2011 wurde zu Beginn der seit der letzten Jahrestagung verstorbenen Mitglieder Winfried Brugger, Karl Doehring, Kurt Gallent, Jörg Müller-Volbehr und Helmut Quaritsch gedacht. Die Vereinigung wird ihnen ein ehrendes Andenken bewahren.

Im gleichen Zeitraum wurden 18 neue Mitglieder in die Vereinigung aufgenommen. Besonders bemerkenswert ist es, dass sich darunter auch eine Kollegin aus Italien (Diana-Urania Galetta) und ein in Italien lehrender Kollege aus Frankreich (Jaques Ziller) befinden.

Die Mitgliederversammlung setzte eine Arbeitsgruppe ein, die sich mit der Thematik „Wissenschaftliche Standards im Öffentlichen Recht“ befassen und für das nächste Treffen der Vereinigung Vorschläge unterbreiten soll. Eine Verschiebung der Jahrestagung um einen Tag zur Vermeidung von Kollisionen mit Vorlesungsverpflichtungen in der Schweiz und an verschiedenen anderen Universitätsorten wurde abgelehnt.

Das wissenschaftliche Programm der Jahrestagung stand unter dem Generalthema „Grundsatzfragen der Rechtsetzung und Rechtsfindung“. Die im vorliegenden Tagungsband wiedergegebenen Referate und - von Wolfram Höfling und Oliver Lepsius moderierten - Aussprachen behandelten die Rationalitätsanforderungen an die parlamentarische Rechtsetzung im demokratischen Rechtsstaat, die Finanzkrisen als Herausforderung der internationalen, europäischen und nationalen Rechtsetzung, die höchstrichterliche Rechtsfindung und Auslegung gerichtlicher Entscheidungen sowie die Rechtsetzungen der europäischen und nationalen Verwaltungen.

Das Rahmenprogramm der Tagung begann, nunmehr schon fast traditionsgemäß, bereits am Vorabend (4. Oktober 2011), an dem die neuaufgenommenen Mitglieder und ihre Mentoren zu einem Begrüßungsessen eingeladen wurden. Am Eröffnungstag (5. Oktober 2011) trafen sich die Gesprächskreise „Europäisches Verfassungsrecht“, „Verwaltung“ und - erstmals - „Grundlagen des öffentlichen Rechts“. Behandelt wurden die Themenstellungen „Die EU als globale Akteurin und ihre Außenverfassung" (Vertragsschlusskompetenz nach Lissabon: 
Demokratische Legitimation der Außenpolitik?, Tobias Jaag; Beitritt der EU zur EMRK und ZP 14: Wirksame Durchsetzung einer gesamteuropäischen Grundrechteverfassung?, Constance Grewe; Die Umsetzung der gezielten UN-Sanktionen durch die EU nach Einrichtung der UN-Ombudsstelle - europäische oder globale rule of law?, Andreas von Arnauld), „Der Beitrag der öffentlichen Verwaltung zur Konsolidierung der Staatsfinanzen“ (Hermann Pünder) und „Das Öffentliche Recht vor der Frage nach seiner Identität“" (Dieter Grimm, Otto Depenheuer, Ewald Wiederin).

Die Tagungsberatungen wurden eröffnet durch ein Grußwort des Dekans der Rechtswissenschaftlichen Fakultät der Westfälischen Wilhelms-Universität Münster, Prof. Dr. Hans-Michael Wolffgang, und umrahmt von zwei abendlichen Empfängen. Der Empfang am Mittwochabend (5. Oktober 2011) wurde in dem - extra durch einen Zeltanbau erweiterten - Schloss der Universität von Rektorin Prof. Dr. Ursula Nelles ausgerichtet. Am Donnerstagabend (6. Oktober 2011) ist die Vereinigung zu einem Staatsempfang in das Wasserschloss Nordkirchen eingeladen worden. Gastgeberin war die Ministerpräsidentin des Landes Nordrhein-Westfalen, die sich durch Justizminister Thomas Kutschaty vertreten ließ. Der festliche Abend am Freitag (7. Oktober 2011) fand im Zwei-Löwen-Klub Münster statt. Abgeschlossen wurde die Tagung mit dem traditionellen Ausflug am Samstag (8. Oktober 2011), der die Teilnehmer zur Burg Lüdinghausen, Burg Vischering und zum Damenstift Nottuln führte.

Der besondere Dank der Vereinigung gilt unserem kooptierten Vorstandsmitglied Janbernd Oebbecke, der zusammen mit seinem Mitarbeiterteam und Münsteraner Fakultätskollegen die Tagung vorzüglich vorbereitet und organisiert hat, so dass die Veranstaltung allen Teilnehmern auch aus diesem Grunde im Gedächtnis bleiben wird.

Dirk Ehlers 